\title{
SOBRE UN GENTILICIO FRUSTRADO: EL PIUCO EN LA HISTORIA DECIMONÓNICA DE CHILOÉ
}

TOMÁS CATEPILLÁN T. ${ }^{a}$

\section{RESUMEN}

En el artículo se desarrolla un ejercicio de historia conceptual en torno a la voz 'piuco', con diversos usos registrados entre el siglo XIX y XX. Se reflexiona sobre sus orígenes, campos de experiencia $y$, específicamente, sobre las expectativas concentradas en algunos usos que se hicieron de este término en torno a la Guerra del Pacífico: como gentilicio en ciernes, a partir de su identificación con los sectores populares de la provincia de Chiloé. Un concepto en el centro de los discursos raciales, se relaciona su trayectoria y diversos significados, tanto pragmáticos como ideológicos, con los procesos que caracterizan la historia decimonónica de Chile y de Chiloé, y se aventura algunas respuestas sobre las posibles causas de la frustración de la voz 'piuco' como gentilicio equivalente del actual 'chilote'. El texto se sostiene en una revisión de diccionarios diferenciales, publicaciones sobre geografía, política y viajes, periódicos de Chiloé y parte del epistolario del intendente Luis Martiniano Rodríguez.

PALABRAS CLAVE: gentilicio, Piuco, Chiloé, siglo XIX, raza.

\section{ABOUT A FAILED DEMONYM: \\ THE PIUCO IN THE NINETEENTH CENTURY HISTORY OF CHILOÉ}

\begin{abstract}
In this article I develop an exercise of conceptual history about the word 'piuco', which has diverse uses recorded in the nineteenth and twentieth centuries. I reflect on the origin, fields of experience and expectatives concentrated in some uses of the concept 'piuco' during the years of the War of the Pacific: a potential demonym, constructed on the basis of his identification with the popular classes of the Chiloé province. It is a concept in the center of the racial discourses, And I relate his trajectory and diverse meanings, both pragmatic and ideological, with the most important process in the nineteenth century history of Chile and Chiloé. Some answers are considered about the possible causes of the frustration of the concept 'piuco' as a demonym equivalent of the current word 'chilote'.

a Profesor del Instituto de Historia de la Pontificia Universidad Católica de Valparaíso y miembro de la Comunidad de Historia Mapuche. $\gg$ tomas.catepillan@gmail.com
\end{abstract}


The text is based on a revision of differential dictionaries, publications on geography, politics and travels, newspapers of Chiloé and part of the letters of the Intendent Luis Martiniano Rodríguez.

KEY WORDS: demonym, Piuco, Chile, nineteenth century, race.

\section{INTRODUCCIÓN}

\section{En el Chile de la época [1835] no existían diferencias regionales de importancia ni subculturas. Gazmuri (1992, p. 11)}

La historia de Chiloé, en lo que corresponde al siglo XIX, es sin duda un período poco conocido y poco estudiado. Las recientes publicaciones de Morales (2014 y 2016), León León (2015a y 2015b), Urbina (2016) y Aravena (2017), han contribuido a adelantar algunos aspectos de los chilotes de aquel primer siglo de nuestra historia republicana ${ }^{1}$. Pero, a decir verdad, aún son muchas las dudas que existen respecto de aquella provincia: dudas respecto de los modos en que se relacionó con la República de Chile, respecto de los modos en que se lidió con su particular herencia colonial, o respecto de los procesos mediante los cuales se atenuaron aquellos elementos que hicieron de Chiloé la provincia más extraña en el contexto chileno.

En este artículo se pretende contribuir con un elemento en concreto al desbroce de la historia de Chiloé, aunque para hacerlo, parece, también se contribuye a la historia de Chile en lo que toca a los conceptos que tempranamente sirvieron para rearticular los discursos raciales en esta república sudamericana: ¿qué gentilicio utilizar para la totalidad de la nación? ¿con qué términos denominar a las clases populares? ¿qué gentilicios usar para las distintas provincias? ¿y qué significados y expectativas concentraron estos conceptos?

Como señala el epígrafe de esta sección, no es rara la idea entre ciertos historiadores nacionales de que la República de Chile, por ejemplo a mediados del siglo XIX, se caracterizaba por su homogeneidad cultural. Se trata de una idea

1 Cabe agregar a la lista del párrafo el artículo de Llorca-Jaña et al. (2018), que no se ha tenido tiempo de revisar. La segunda publicación de León León se trata en general de un compendio de artículos que ya se habían publicado en diversos medios.

2 Se cita en lo sucesivo a Salinas, Pinto, Cornejo, Cid, que parece haber permeado inclusive en nuestra legislación, a pesar de los conocidos casos que contradicen esta pretensión, desde la existencia ineludible de las naciones mapuche, rapa nui, aymara, etc., hasta los procesos más actuales de migración que claramente están contribuyendo a imaginar una nueva faz chilena.

Son múltiples las formas a través de las cuales podríamos discutir con Gazmuri aquella idea de un Chile homogéneo, aunque es probable que si limitamos la idea de dicho país exclusivamente al país del Mapocho, efectivamente nos encontremos con una reconfortante homogeneidad. En otras palabras: el centralismo y la pretendida homogeneidad de aquella república sudamericana son dos caras de un mismo fenómeno, y éste es capital en la construcción del Estado-nación chileno. Atendamos a los márgenes de aquel Chile para observar sus diferencias.

Una nota antes de seguir con el artículo. Es claro que en este texto se dialoga con los historiadores de Chiloé mencionados, así como con cierta historiografía relativa a Chile, específicamente, aquella que se ha preocupado por los aspectos culturales de la política y del nacionalismo chileno de mediados y fines del siglo XIX ${ }^{2}$. Aquí, de todos modos, también se realiza un ejercicio que podría ubicarse dentro del ámbito de la historia conceptual, entendiendo que lo que interesa es seguir las huellas, ¡tenues y dispersas!, de un término polisémico en las décadas centrales del siglo XIX. Pero se trata de un concepto marginal cuyo principal interés, me parece, reside en el potencial que tenía, en sus usos contradictorios y en su final transformación en una palabra totalmente anodina. Con esto, como puede suponerse, por una parte nos acercamos a aquella obra monumental de Reinhart Koselleck ${ }^{3}$, con brotes igualmente monumentales como lo es el proyecto Iberconceptos ${ }^{4}$, pero por la otra, nos

Gutiérrez, etc

3 Ver Koselleck, 2012.

4 Ver el Diccionario político y social del mundo iberoamericano. La era de las revoluciones, 1750-1850 (Fernández, 2009). 
alejamos de estos referentes ineludibles. He aquí que el concepto piuco no es ahora, ni lo fue en las décadas que nos interesan, un concepto central ni básico en la política decimonónica de las provincias australes. Se espera a lo largo del texto ver la importancia de estudiar asimismo estos conceptos perdidos, hoy insignificantes, que en su momento contuvieron en latencia significados fundamentales, y por lo mismo, que pudieron estar atravesados por importantes expectativas.

\section{PUEBLO CHILOENSE Y PUEBLO CHILENO}

Como se espera mostrar en otro lugar, no son pocas las publicaciones del siglo XIX que abordan las diferencias culturales de los chilotes y que se detienen en ellas para explicar la provincia, de cara a sus audiencias inglesas o chilenas. En la mayoría de esas publicaciones, sin embargo, este reconocimiento se hace implícitamente. Por lo mismo nos detenemos en una que lo explicita: el Chile ilustrado de Recaredo Santos Tornero, aparecido en 1872.

Este libro es una "optimista descripción de cada región del país y de los adelantos de una incipiente modernidad y estabilidad institucional" (Cornejo, 2005, p. 164) que entre otras cosas tenía la pretensión de describir "los usos y costumbres más resaltantes de nuestra sociedad" (Tornero, 1872, p. vi). Lo que me interesa destacar es que, si bien la tercera parte del Chile ilustrado se dedica exclusivamente a describir estos "usos y costumbres de nuestra sociedad", la descripción de la sociedad chiloeña no se realiza en ese apartado, como sí pasa con las demás provincias chilenas. La sociedad de Chiloé es descrita exclusivamente en la sección dedicada a dicha provincia. El autor nos explica el porqué:

Si bien el estado material de la ciudad de Ancud no ofrece para nosotros una gran importancia, no sucede lo mismo con

5 Se publicó en los Anales de la Universidad de Chile. De todos modos Tornero es confuso en esta referencia, puesto que da el autor de esta publicación pero le asigna el nombre de otra publicación sobre Chiloé: Anónimo, "Bosquejo jeográfico de la provincia de Chiloé", con una errata notable, además, ya que imprimieron 'Chile' en cambio de 'Chiloé' (Tornero, 1872, p. viii). El "Bosquejo jeográfico de respecto a ciertos usos y costumbres del pueblo. Damos pues a continuación algunos datos que ofrecen una idea bastante exacta, aunque muy a la ligera, de ciertos hábitos peculiares de los moradores del estremo Sur de nuestro territorio (Tornero, 1872, p. 384).

Y no sólo era una cuestión de usos y costumbres peculiares. En Chile, nos dice Tornero, era el término roto la voz con que se denominaba al personaje típico de la parte más desposeída del bajo pueblo. Un conjunto caracterizado por el mismo Tornero como personas mal alimentadas, mal descansadas, mal vestidas, proclives al juego y a la bebida, vagabundos, sedientos de aventuras, pero, así y todo, cotizados por los empresarios (nacionales y extranjeros) y fuertes a pesar de lo que podría suponerse por su tren de vida (Tornero, 1872, pp. 465-467). En la provincia de Chiloé, en cambio, no habrían existido rotos: era "el piuco" el "nombre con que se designa a los hombres del pueblo" (Tornero, 1872, p. 384). Cosa curiosa, la descripción del piuco que nos adelantó Tornero no se cargó a lo negativo, como sí sucede en su descripción del roto, insistiendo en cambio en dos cuestiones: en su fuerza para resistir los más pesados trabajos en zonas aisladas, sosteniéndose apenas con harina tostada y agua, y en su profunda superstición, poblada de brujos y miedos.

Se desconoce la fuente que habría utilizado Tornero para informarse de la existencia y características del piuco, ya que a pesar de que el autor reconoce los materiales que usó, afirmando que se hizo asesorar por conocedores de las provincias que describe, en lo que toca a Chiloé sólo especifica haber utilizado el "Bosquejo jeográfico de Chiloé", de Pedro Lucio Cuadra, publicado en $1866^{5}$. Junto con Cuadra, también es posible reconocer en su descripción de Chiloé (sin que lo cite) un uso casi literal del Manual de jeografía que publicó su padre, Santos Tornero, en $1862^{6}$. De

la provincia de Chiloé" se publicó en Valparaíso (Imprenta del Mercurio, 1851). Ni el texto de Cuadra ni el anónimo de 1851 hacen referencia a los piucos.

6 El libro de Santos Tornero se escribió ajustándose al programa de la Universidad de Chile y a las Lecciones de Lastarria. Conoció bastantes ediciones, al menos hasta 1895 (ver el catálogo de la Biblioteca Nacional). 
todos modos, en ninguna de estas obras aparece el término 'piuco', como sí aparece en un trabajo de 1864 firmado por Carlos García-Huidobro ${ }^{7}$, no citado por Tornero hijo, en el que se utiliza la voz para referirse a "la gente baja" de Chiloé (p. 467), además de usarse para insistir en la separación tanto geográfica como cultural de la provincia de Chiloé respecto del país del cual formaba parte.

Aclarado el asunto con Tornero en 1872, saltemos adelante en el tiempo, a 1887, que es cuando Alejandro Cañas Pinochet visitó por última vez la provincia antes de publicar su "diccionario" del mapudungún ${ }^{8}$ de Chiloé, en 1910, y oigamos su definición de 'piuco': "palabra con que se designa al hombre del pueblo en Chiloé y que se aplica por desprecio a todos los chilotes" (1910, p. 313). Y para no perder la década, oigamos por último a Ramón Espech, quien visitó la provincia en 1882, y que definió 'piuco' como "nombre genérico con que se designa al indígena chilote" 9 .

En resumen, siguiendo a este conjunto de autores tendríamos que al menos entre 1860 y fines del siglo XIX habría existido un nombre específico para referirse al personaje popular de Chiloé, alternativamente identificado con el indígena de la provincia, y por extensión, fuera de la provincia (¿en las provincias vecinas?), para referirse a todo aquel que proviniese de Chiloé. Más allá de lo importante que parece que lo popular chiloense y lo indígena se fundieran en una sola categoría, lo que interesa destacar en esta sección es que el término, siendo lo importante que pudo llegar a ser si lo comparamos con su análogo chileno (roto), cayó para principios o mediados del siglo XX en el olvido ${ }^{10}$. E insistimos, entre 1870 y fines del siglo XIX, porque a este breve arco de tiempo corresponden todas las muestras de su uso que se han podido ubicar, incluyendo las publicaciones mencionadas, las comunicaciones privadas de al menos un intendente de la provincia y la prensa local.

7 Se publicó en los Anales de la Universidad de Chile y en tirada aparte.

8 Idioma del pueblo mapuche. El término se ha castellanizado.

9 Archivo Nacional Histórico de Chile, Fondo Varios, vol. 246 pieza 9 foja 166v, sin fecha.

$10 \mathrm{Y}$ en esto es bien decidor el hecho de que no figure el término ni en los vocabularios ni en la trama de ninguna de las tres novelas costumbristas sobre Chiloé publicadas entre 1914 y 1944: Vida isleña (1914) de Darío Cavada, Gente en la isla (1938) de Rubén Azócar y Huipampa, tierra de
Sigamos pues, con una breve disquisición en torno al término 'roto', para sopesar el derrotero de un término análogo al que interesa, aunque cobijado por una nación en formación, para luego seguir con una discusión sobre las variantes del término 'piuco', sus posibles etimologías, procedencias y destinos, para terminar con una reflexión hecha por el escritor Martín Palma a propósito de la necesidad de convocar al pueblo en el esfuerzo de la guerra, pero ajustándose a la realidad de cada quien, específicamente, como lo aclarará Palma, ajustándose a las diferencias entre el piuco y el general Pililo. En otras palabras, entre el pueblo chiloense y el pueblo chileno.

\section{EL ROTO PILILO}

Con independencia de los supuestos orígenes biológicos del bajo pueblo en el país del Mapocho, es decir, con independencia de si era mestizo ${ }^{11}$, descendiente del "araucano" y en qué "porcentajes", es un hecho probado que para las décadas de 1870 y 1880 "la personificación más representativa de lo popular" era el roto (Cornejo, 2005, p. 167). La imagen de un hombre adulto, representado generalmente solo, que oscilaba entre el miedo y el desprecio, por el lado de la mirada tradicional de la élite nacional, y su reivindicación positiva, por el otro ${ }^{12}$. En lo que toca a su reivindicación, y más importante aún, a la posibilidad de integrarse en el discurso nacional, parece ser también algo claro que fue, en términos de Maximiliano Salinas, "la causa nacional de la Guerra del Pacífico la circunstancia que hizo destacar a los mestizos como parte integrante de la causa de la élite" al permitir que "tanto huasos como rotos" pasaran "a constituir miembros activos de la vida nacional" (Salinas, 2004, p. 218). En términos más precisos, que la Guerra del Pacífico fue la "coyuntura precisa para la movilización por

sonámbulos (1944) de Nicasio Tangol.

11 Dejamos para otra ocasión la discusión sobre el mestizo y el mestizaje como ideologías específicas, afines al proceso de construcción de la nación, y para nada categorías transparentes, como usualmente son utilizadas en la historiografía chilena.

12 Ver e.g., Salinas, 2004, que se centra en particular en el discurso de Juan Rafael Allende respecto de este estereotipo. 
parte de la élite del roto como ícono nacional, pues propició en la sociedad chilena una etnización clara del nacionalismo" (Cid, 2009, p. 232). Una "etnización" que se iniciaría como consecuencia de la necesidad de movilizar tropa hacia el norte, pero que llegaría a niveles insospechados, con un climax luego de los triunfos de Chorrillos y Miraflores en enero de 1881, con particular énfasis en la supuesta filiación guerrera del roto.

Esta "oportunidad de objetivar sus vínculos con la nación" que la coyuntura bélica ofrecería al bajo pueblo (Ortega, 2005, p. 429), y que contribuiría a la larga a la fijación discursiva de "la imagen épica del roto como base última de cohesión social y gloria nacional" (Pinto, 1997, p. 55), tendría dos consecuencias, una proyectiva y otra retroactiva. La proyectiva sitúa esta primera inclusión del tipo popular como un reconocimiento simbólico de pertenencia que luego, en los años inmediatos a la Guerra del Pacífico y las décadas siguientes, se traduciría en un reclamo por el reconocimiento concreto, constituyéndose en una de las múltiples vías de la organización política de los sectores populares y de las teorías nacionalistas del siglo XX (Pinto, 1997, p. 56) ${ }^{13}$. La consecuencia "retroactiva", por otra parte, hizo de esta inclusión un desafío presente y porvenir que requirió de una genealogía histórica que reafirmara los valores del roto y su vínculo indefectible con la nación. Ésta podría resumirse en el esfuerzo por vincular el estereotipo del roto con los afanes guerreros del coloniaje (el roto chileno descendería alternativamente de los mapuches, los conquistadores europeos, los soldados de la frontera y a la vez de todos ellos), con la guerra de independencia y más importante aún, para la década de 1880, con la guerra contra la Confederación Perú-Boliviana. Esto es precisamente lo que se sancionó con la erección del Monumento al roto chileno, en 1888, utilizando una estatua que originalmente representaba un soldado de la Guerra del Pacífico, para tributar un inédito reconocimiento al esfuerzo del roto en la batalla de Yungay (20 de enero de 1839) (Cid, 2011, pp. 203, 207, 210, 219).

Como puede suponerse, este proceso de construcción de un mito a partir de un tipo popular no implica que la población susceptible de ser catalogada como rota fuese luego de 1883 una población identificada con la nación. Bastante claro es Sater (1986, p. 77) al afirmar que, previo a la Guerra de 1879 e incluso en los años inmediatos, los rotos del país llamado Chile como mucho se identificaban con su fundo o hacienda, siendo incluso raro que se identificaran con la provincia de donde procedían. El éxito del ícono roto, por otra parte, tampoco supuso que la visión elitista y negativa del roto dejase de operar, ni que dejasen de operar los mecanismos orientados a marginar al bajo pueblo de los discursos nacionales e incluso de su vida política y social. De modo que la imagen del roto, devenido en ícono, facilitaría el proceso de construcción popular de la nación, a pesar de estar en constante actualización y disputa con la imagen negativa de sí mismo (Cid, 2011, pp. 188 , 195, 199), podría decirse, incluso, hasta la actualidad. Es posible pesquisar esta polisemia en las definiciones que se dieron del término, lo que se comenta brevemente de modo de ilustrar, posteriormente, lo que aconteció y pudo acontecer con el piuco de Chiloé.

El primer diccionario de chilenismos que recogió el término 'roto' es el de Zorobabel Rodríguez, publicado en 1875. En lo que interesa, el autor aclara que el término es voz castiza, en su acepción de zarrapastroso, andrajoso, y que la acepción peculiar de "nuestro uso" sería la de identificar a los rotos con "la gente de última clase" (ver entrada 'roto'), con lo que se volvería un sinónimo de la voz 'pililo', netamente chilena (ver entrada 'pililo'). La carga negativa del término, la que provendría de su acepción castiza, sería ponderada por el mismo Rodríguez al aclarar en la entrada 'cholo' que, si bien serían voces análogas, "la gente de última clase" peruana y chilena serían semejantes en la composición de su sangre (mestizos), pero bien distintos en sus cualidades, siendo el cholo débil, palangana, expansivo y más artista ("un andaluz injerto en indio peruano") mientras que el roto, robusto, enjuto, reservado y esforzado ("un vizcaíno injerto en araucano") (Rodríguez, 1875, entrada 'cholo').

Fuera de este contraste y las supuestas cualidades de las "últimas clases" del Perú y Chile, que tendrían amplia divulgación en las prensas chilenas durante los días de la Guerra del Pacífico,

13 Ver también Gutiérrez (2010) y Cid (2011, pp. 217-218) (en referencia al trabajo del profesor Sergio Grez). 
lo interesante es que fuera de Chile el término pasaría a adoptarse como sinónimo de chileno, según lo recogería J.T. Medina en sus Chilenismos, de 1928 , en plena concordancia con la $5^{\text {ta }}$ y $6^{\text {ta }}$ acepción que recogería la Real Academia de la Lengua Española en sus diccionarios publicados entre 1925 y 1992: "5. m. Chile. Individuo de la clase ínfima del pueblo. 6. Argent. y Perú. fam. despect. Apodo con que se designa al chileno"14.

Se ve cómo un término usado para referirse con desdén al bajo pueblo contenía la posibilidad de mutar hacia un apodo utilizado incluso cariñosamente $e^{15}$, aunque llevando siempre consigo la mácula original que le permitiría también volverse el apodo despectivo con que seríamos denominados, en los países vecinos, todos los habitantes de la República de Chile. Fuera de las fronteras, el término se nacionalizaría despectivamente, mientras que al interior, se intentaría (con éxito relativo) nacionalizar el término cariñosamente. Volvamos ahora al piuco, que muchos de estos procesos se pueden encontrar en sus diversas definiciones y usos.

\section{EL PIUCO DE CHILOÉ}

Las definiciones de la voz 'piuco' dadas hace algunos párrafos, clarificadoras, si bien nos dan una pista importante respecto del uso que habría tenido, ocultan su extensión geográfica, sus posibles etimologías y procedencias, y las variaciones semánticas que experimentaría a lo largo de su corta vida.

En los principales periódicos que se publicaron en Chiloé durante 1868 y 1890, el término 'piuco' aparece marginalmente, y con diversidad de acepciones. En El Chilote, periódico de tendencia liberal publicado entre 1868 y 1886 , no hay ninguna mención explícita del término en sus editoriales y notas propias de la redacción, exceptuando su mención como apellido de uno de los fusilados junto al

14 Diccionario RAE (1925), entrada 'roto', la definición varía recién en 1992. En Medina (1928) se define el término del siguiente modo: "Argen. y Perú. fam. despec. Apodo con que se designa al chileno. (En Chile, al hijo del pueblo)".

15 Ver e.g., de Nicolás Palacios su Raza chilena, de 1904. Define el término roto como "apodo nacional chileno".

16 Ver e.g., el remitido de Francisco Miranda Velásquez, chacha Nahuelhuén, en 1879. De todos modos, también es cierto que los sucesivos redactores omitieron hablar de indios (como mucho, hacen menciones de los "indígenas"), a pesar de que éstos abunden en los diálogos de personajes populares ficticios (e.g., en edición del 19/11/1868), en las notas costumbristas (e.g., en edición del 31/10/1874), en las noticias de los mapuches de Arauco (e.g., en ediciones del $23 / 12 / 1869,20 / 5 / 1870$ y $24 / 2 / 1881$ ) y en los artículos remitidos del interior, apareciendo incluso en asociación a su contrario colonial, el español, siguiendo su definición pre nacional ${ }^{16}$. La situación cambiaría para 1885, cuando el periódico pasa a ser controlado por el editor de la publicación del obispado, El Católico. Bajo la nueva línea editorial se utilizaría en sus primeros dos números el término 'piuco' para referirse a una persona licenciosa, para referirse a una "persona del pueblo" y, finalmente, para referirse sencillamente a un habitante de Chiloé (ediciones del 23/5/1885 y 30/5/1885).

Más ambiguo es el uso que se hace del término en La Probidad (1885-1890). La única mención que aparece en este periódico ancuditano es una supuesta "carta de un piuco", llamado Jacinto Remolcoi, dirigida a su paisano Anastasio Peranchiguai (edición del 22/7/1887). Se trata de una carta ficticia destinada a informar sobre la situación actual en Ancud a partir de las impresiones de un piuco, que, se entiende a lo largo de la carta, sería alguien ajeno a Ancud: un habitante del interior de la provincia, a diez días de navegación a vela de la capital. Un habitante del interior, más todavía, que por vocabulario, nombre y experiencias que le inventan, parece querer decirnos que junto con ser piuco o precisamente por serlo, era además indio, católico, ignorante y sin "posición social" (a pesar de que el editor se cuidó muy bien de evitar cualquier mención de la indianidad). El Liberal, por último (1878-1885), tampoco publicó ninguna mención a los piucos de

publicado en El Chilote del 27/6/1878, sobre los crímenes del chacha Nahuelhuén, en que aclara que "el desgraciado joven don José del C. Álvarez fue asaltado en unión de sus cuatro compañeros dos españoles o blancos y dos indios a la salida de Melincka por una chalupa y un bote tripulados por veintidós indios". 
Chiloé, exceptuando un artículo de fondo escrito por Martín Palma que se comentará más abajo ${ }^{17}$.

Más acotado en el tiempo, pero no por ello más claro en su uso, el término 'piuco' también aparece recurrentemente en las comunicaciones particulares del intendente Luis Martiniano Rodríguez a Domingo Santa María, ministro de gobierno y, a partir de 1881, Presidente de la República. Así, desde su mera entrada a la provincia como Intendente en 1878, Rodríguez hace referencia a los piucos dando por sentado su significado al señalarlos como responsables del mal estado de la educación en la provincia ${ }^{18}$, para justificar el poco entusiasmo que suscita la guerra $^{19}$, para indicar la suspicacia que podría provocar en el pueblo el hecho de que no llegase a tiempo su nombramiento ${ }^{20}$, para desprestigiar a los políticos locales ${ }^{21}$, para dar a entender que todo el pueblo apoya su candidatura presidencial ${ }^{22}$. En fin, ejemplos sobran para mostrar que el significado del término 'piuco' oscila en el Intendente Rodríguez entre un uso acotado a lo popular y un uso irónico, que abarca incluso a los notables locales, no siendo posible saber qué tanto participaba su uso del contenido indígena que señaló Ramón Espech y que se ha visto en las pocas menciones reseñadas de la prensa local. De todos modos, lo que más llama la atención es que, siendo una denominación local o al menos pareciendo una denominación local según las definiciones de Recaredo Tornero, Alejandro Cañas y Ramón Espech, el intendente Luis Martiniano Rodríguez la haya utilizado en sus comunicaciones con Santa María sin aclarar en ningún momento su significado ${ }^{23}$. Aunque son dos personajes notables, sobre Rodríguez y Santa María hay que aclarar aquí que indudablemente pertenecían al país del Mapocho. ¿Será posible

17 Dentro de los principales periódicos chilotes del período faltaría agregar El Católico (1884-1891), que cambió dos veces de nombre en la década de 1890, para seguir publicándose como La Cruz del Sur entre 1898 y 1983.

18 Archivo Nacional Histórico de Chile, Fondo Domingo Santa María (en adelante ANH.DSM), documento B6891, carta del 19/2/1878.

19 ANH.DSM, documento A8746, carta del 5/5/1879.

20 ANH.DSM, documento C2777, carta del 5/1/1880.

21 ANH.DSM, documento C2778, carta del 5/2/1880.

22 ANH.DSM, documento C5120, carta del 6/3/1881.

23 A menos que la carta en que define el término no se encuentre conservada en el ANH.DSM. encontrar una respuesta a este problema en los diccionarios coetáneos? Vayamos de mediados del siglo XX hacia atrás.

El diccionario "chilote" con el que partimos es el de Nicasio Tangol, quien publicaría en 1976 su Diccionario etimológico chilote. De todos modos, el trabajo dataría de 1967, y más aún, según su introducción, se habría basado en su experiencia en la Isla Grande, donde habría residido durante sus primeros dieciocho años de vida (1906-1924). ¿Su definición? 'piuco', voz usada para referirse a una "combinación desacertada de colores en las prendas de vestir; prenda recargada de colores" (entrada 'piuco'), sin que señale etimología ni fuente alguna.

Un poco más completo, aunque tampoco informa de las fuentes que habría utilizado para componer los "Vocablos y modismos del lenguaje de Chiloé"24 que publicaría en los Anales de la Universidad de Chile (1947), Agustín Álvarez define 'piuco' como: "individuo charro [de mal gusto] en vestir y también persona que, por su falta de trato social, se avergüenza al presentarse ante la gente y no puede hablar ni corresponder a las atenciones que se le hacen. Hay en el departamento de Quinchao un distrito llamado Piúcos" (entrada 'piuco'). Con lo que podríamos acercarnos a una posible etimología (vocablo derivado del nombre de un distrito) y a una acepción más cercana a la que habría operado en las décadas de 1870 y 1880.

Entre estos trabajos y el de Alejandro Cañas Pinochet, ya citado, no sólo correrían cerca de cuarenta años, sino además una diferencia fundamental: Cañas Pinochet levantó un diccionario específicamente del mapudungún de Chiloé, o veliche, mientras que Álvarez Sotomayor parte de la premisa de que "aunque viven en Chiloé varios

24 De todos modos, el autor afirmó que era originario de Chiloé y que compuso el trabajo a partir de su conversación con sus comprovincianos. En el apéndice se pueden leer pasajes como el siguiente: "Viven todavía en la provincia algunas víctimas de la agarradura de gente del 91 . Hemos hablado, hace poco tiempo, con una de estas personas, un señor Soto, agricultor del departamento de Quinchao. Nos relató la forma en que fue prendido y el susto que pasó en la batalla de Placilla, de la que cree se salvó merced a su fe en la Virgen del Carmen y al recuerdo de su adorada madre que había quedado en completo abandono con su forzada ausencia" (Álvarez, 1947, pp. 152, 154). 
indígenas centenarios, ninguno de ellos habla el idioma de sus antepasados" (1947, p. 66). Y qué decir de Nicasio Tangol, para quien el veliche no era otra cosa que el "idioma que usan los brujos" (1944, p. 307).

El tercer y último autor que interesa de los dedicados a registrar "chilotismos", contemporáneo de Alejandro Cañas, es Francisco Cavada. Sacerdote, autor prolífico y figura central en el grupo de "chilotistas" de principios del 1900, se orientó sobre todo a la creación del folclor de Chiloé, de donde era originario y donde vivió al menos entre 1864 y $1895^{25}$. Sus principales obras sobre el tema, emparentadas, se publicarían en 1910, 1912-13-14 y 1921, con los títulos, respectivamente, de 1) Apuntes para un vocabulario de provincialismos de Chiloé (República de Chile): precedidos de una breve reseña histórica del archipiélago; 2) Chiloé y los chilotes y 3) Diccionario Manual Isleño. Provincialismos de Chiloé (Chile). En su obra más importante, Chiloé y los chilotes, resultado de los Apuntes y una versión más abundante del Diccionario manual, Cavada aclara que se remitió a los únicos dos diccionarios específicos sobre el idioma de los indios de la provincia ${ }^{26}$, acotándose a seguirlos en compañía del Diccionario etimológico de Rodolfo Lenz, así como al registro que hizo de los usos de "nuestros labriegos y pescadores" durante cinco años (Cavada, 1914, p. 263), excluyendo las palabras que se definen en los diccionarios de chilenismos, de americanismos y en los de la Real Academia de la Lengua Española. Veamos sus definiciones, para no seguir abultando, que son coincidentes en sus tres publicaciones.

Piuco no figura como entrada propia, apareciendo en cambio la entrada 'piuque',

25 Nació en Ancud. En 1916 fue nombrado miembro de la Academia Chilena de la Lengua, y en 1933, miembro correspondiente en Chile de la RAE. Para una biografía parcial del autor, ver Cavada (1940, pp. 132-134).

26 Se trata del diccionario de Cañas Pinochet y de un calepino compuesto por el jesuita Gaspar López, a principios del siglo XVIII, utilizado por el padre Febres para componer su Arte de la lengua general del reyno de Chile [...] (1764).

27 Ver la entrada 'piuque' en Cavada (1914 y 1921).

28 Ver la entrada 'llaulle' en Cavada (1910).

29 Ver la entrada 'llaulle' en Cavada (1914).

30 La definición que se da de 'llaulle' en Cavada (1921), en cambio, descarta la voz 'piuco' y se queda exclusivamente derivado del mapuche (corazón), con la acepción de "bofes de las reses" 27. Aparece, eso sí, una nota importante en la definición de otro término hasta aquí ignorado: 'llaulle', "equivale al chileno piuco, rústico, cerril, encogido, huraño"28; "Piuco, rústico, cerril, encogido, huraño". Probablemente del chileno "lleulle: persona cobarde, inútil, inepta" (Cañas) ${ }^{29}$. Ambas definiciones de 'llaulle'/'lleulle', dadas entre 1910 y $1914^{30}$, incluirían la voz chilena 'piuco', que de todos modos, tendría un origen mapuche ${ }^{31}$. ¿Sería, según esto, un término proveniente del continente, usado despectivamente para referirse a los habitantes de Chiloé: rústicos, cerriles, encogidos, huraños? Esto podría explicar que tanto Luis Martiniano Rodríguez como Domingo Santa María comprendieran el término, con independencia de los chiloenses. Podían ser piucos también los inquilinos de sus haciendas en la zona central, los baqueanos del Norte Chico, en fin. Cualquiera, incluidos los gentiles de Chiloé. Pero de ser esta la única posibilidad, ¿de dónde provendría la idea de que piuco se usaría para definir al "hombre de pueblo" en Chiloé, y a todos los chilotes fuera de la provincia (Tornero, 1872 y Cañas, 1910), así como para designar al "indígena chilote" (Espech en 1882)? ¿Cómo podría un término chileno adoptar una acepción tan regional?

Sigamos con otros diccionarios, pero ahora específicamente de voces chilenas. El primero es el Diccionario de chilenismos y de otras voces y locuciones viciosas de Manuel Antonio Román, cuyo tomo 4 (letras N-Q) se publicó entre 1913 y 1916. El cual, dios mediante, incluye las voces que interesan y considera matices regionales. De modo que podemos leer una definición de 'llaulle' calcada de la dada por Cavada, y una definición de 'piuco' que es como sigue:

con "el chileno lleulle=inepto, inútil". En lo demás coinciden.

31 En su advertencia al vocabulario Cavada distingue palabras de origen castellano, chileno e indígena (1914, p. 286). Sin embargo, el uso que hace del término chileno, y aun el tipo de palabras que califica como teniendo este origen, en cierto sentido sigue participando del uso más antiguo de aquella voz, que denominaba a la población indígena del Reino de Chile. Un caso más claro se puede apreciar en la Relación genealógica (1911) de Luis Mansilla, en la cual arcaicamente se refiere al mapudungún como el idioma "chileno". 
En las provincias australes (Valdivia, Llanquihue y Chiloé) dan este nombre al individuo de genio corto, apocado, cerril, de poco trato. (Fidelis P. del Solar).- Nombre despectivo que se da fuera de su provincia, al habitante de Chiloé o chilote.- Parece que viene del araucano piuque, que allá mismo significa bofe de res; según lo cual, piuco equivaldría a bofero, ra: que se alimenta de bofes. (Bofero no aparece en el Dicc., pero está bien formado y lo hemos visto en buenos autores) (Román, 1901-18, v4, entrada 'piuco').

Con lo que llegamos a una definición que reconoce usos diferenciados por provincia (el término no es de uso en todo Chile, sino sólo en las provincias australes) siendo el calificativo tanto para una persona huraña, como para una persona proveniente de Chiloé, en cuyo caso se aplica despectivamente. La etimología, por último, habla de una mixtura idiomática: se trataría de un sustantivo propio del mapudungún convertido en adjetivo siguiendo las normas de formación de palabras del castellano. Pero no nos quedemos ahí. El diccionario de Fidelis P. del Solar ${ }^{32}$, citado por Román, nos informa de un momento importante de la historia de la voz:

PIUCO, A: En las provincias australes $^{33}$ dan este nombre al individuo de genio corto, apocado, cerril, de poco trato; es, en fin, el guaso en todas sus acepciones. Así como en el resto de la República dice una madre a su hijo: "no sea, guaso, hijito", en Valdivia, Llanquihue y Chiloé le dicen: "no sea piuco" (Del Solar, 1875, entrada 'piuco').

No existiría, de seguir a del Solar, todavía una asociación entre piuco y chilote, sino exclusivamente una acepción despectiva.

32 Reparos al Diccionario de chilenismos del señor don Zorobabel Rodríguez, publicado en 1875.

33 Se imprimió "centrales" y se reconoce la equivocación en la Fe de erratas inserta.

34 Buen conocedor del mapudungún, es dable suponer que pensó en su derivación del sustantivo piuque (corazón), y que rechazara la idea sugerida por Román algunos
Considerando, sin embargo, que Recaredo Tornero luego de entrevistarse con "conocedores de las provincias", definió en 1872 el término exclusivamente en su acepción de adjetivo gentilicio, es presumible pensar que para la década de 1870 ambas acepciones convivían, particularmente en las provincias del sur (Chiloé, Llanquihue y Valdivia), separadas del país del Mapocho hasta la definitiva ocupación de la Araucanía histórica en 1883. Por último, que estas acepciones estarían en pugna y que denominarían en el sur de Chile al "tipo del bajo pueblo", el equivalente sureño del roto del país del Mapocho, también lo confirma Rodolfo Lenz en su Diccionario etimológico, publicado originalmente en 1904 (1976, entrada 'piuco'), a las veces que reconoció no saber cuál podría ser su etimología ${ }^{34}$.

Como puede verse, siendo una palabra polisémica para la coyuntura que interesa, y más aún conteniendo significados disímiles aunque en vías de constituirse en una especie de gentilicio despectivo (al igual que el actual 'chilote'), el término decantaría a principios del siglo XX en una acepción que había sido marginal a fines del siglo XIX, incluso más, podría decirse, totalmente anodina: el mal gusto en el vestir. Un atributo, quizá, de la gente huraña y cerril. Un atributo, quizá, del piuco de Chiloé, ¡del tiempo en que existían piucos de Chiloé! Concluyamos con la reflexión de Martín Palma sobre estos piucos mal vestidos, entre quienes vivió por los años de 1879 a 1880 o 1881.

\section{EL PIUCO Y EL ROTO O EL CHILOTE Y EL GENERAL PILILO}

Como he dicho poco respecto del pililo, al menos en comparación a su gemelo el roto, parece prudente seguir con los diccionarios. Zorobabel Rodríguez definiría este vocablo, en 1875, como término "menos usado que roto, que es el calificativo que sirve de ordinario para designar a los individuos de la última clase, a los

años después. La poca cantidad de ganado vacuno en la isla de Chiloé durante todo el siglo XIX, sin embargo, podría fortalecer hipotéticamente la etimología propuesta por Román, aunque forzando los bofes de la res y transformándolos en las más genéricas entrañas, alimento de los pobres. 
más pobres desaliñados y zarrapastrosos, tiene una significación muy semejante" (entrada 'pililo'). ¿Y el general Pililo? Nuevamente con Román, aunque en una acepción posterior al período que interesa:

Pililo. Chilenismo antiguo y de uso general. El pililo es el individuo de última clase, desarrapado y andrajoso. Lo característico en él no es la ociosidad ni lo pícaro, ni lo vagabundo, ni siquiera lo sucio o asqueroso, sino únicamente la suma pobreza del traje, que todo es andrajos $y$ harapos. [...]. El buen humor y el buen sentido chileno reunió en un personaje ideal el valor de nuestro pueblo, su talento militar $y$ el desprecio en que tiene su propio traje, y creó el General pililo, nombre que nunca existió, pero que cada uno de nuestros rotos lo puede llevar con todo honor; por eso el instinto popular bautizó así la estatua erigida al roto chileno en la plaza de Yungay de esta ciudad (Román, 1901-18, v4, entrada 'pililo').

Ya se ha hablado, aunque brevemente, de esta estatua con la que se pretendió erigir una genealogía guerrera del roto, vinculando su supuesta participación en el triunfo de 1839 con el triunfo de 1881 (Cid, 2011, pp. 210, 216). Que esta estatua haya sido bautizada como general Pililo no consta sino es por la referencia de Román. El término, de todos modos, existiría para la época, p.e., utilizado como nombre por un periódico satírico de la década de $1890^{35}$ y, siguiendo a Martín Palma, como una expresión usada para hacer referencia al "indómito" "roto del Norte, [el] General Pililo, como se acostumbra llamarlo" (El Liberal, edición del 11/6/1880). En otras palabras, y es el uso que se ve a lo largo del artículo que se comenta, como sinónimo de roto, aunque, de manera "un tanto hiperbólica", para hablar del roto en armas llamado al frente de batalla luego de la invasión a Antofagasta en febrero de 1879 (El Liberal, edición del 11/6/1880).

35 El Jeneral Pililo, de J.R. Allende, publicado entre 1896 y 1902.

36 Se pueden leer algunos esbozos biográficos de M.P. en Villalobos (2009), Stuven (2009), Schelchkov (2013) y Figueroa (1897, 1901), tomo II, p. 442. Lo de cenobita
Antes de seguir en el perfil de este "general pililo" y de este "piuco chilote" a partir del artículo "El general pililo y el chilote. O la guerra y sus exigencias. La provincia y sus necesidades", obra de Martín Palma, publicado en El Liberal el 11 de junio de 1880, detengámonos un poco en su autor, que, a riesgo de entrampar la lectura de esta sección, nos aportará elementos importantes para comprender sus posiciones.

Nacido en Santiago en 1821, moriría en esa misma ciudad el 21 o el 22 de febrero de 1884, habiéndose desempeñado en su vida como estudiante de humanidades y derecho, aventurero en California, redactor de El Mercurio y otros periódicos, redactor de sesiones de la Cámara de diputados, escritor de novelas y de estudios político-sociales, curtidor, profesor e incluso cenobita durante un par de años en su retiro chiloense $^{36}$. Fue, luego de su muerte y durante prácticamente todo el siglo XX, olvidado por los estudiosos de la literatura chilena, e incluso por los estudiosos de las ideas políticas y sociales del siglo XIX. Según Figueroa (1897, 1901, tomo II, p. 443), se trató de un "escritor hábil e ilustrado que evidenció firmeza de convicciones liberales" que, sin embargo, no habría pasado de ser un personaje secundario o, siguiendo siempre a Villalobos (2009, p. 8), que no habría pasado de pertenecer a un "sector medio de la clase política", dedicado sobre todo a la difusión de "los grandes pensadores europeos". Entre el racionalismo y el liberalismo más radical de mediados del siglo XIX, Stuven (2009, pp. 25-27, 31, 39) lo califica como un "humanitarista idealista" con posturas igualitarias, autor de una "ácida crítica social", profundamente anticatólico, anticlerical, antioligárquico, vinculado ideológicamente con Francisco Bilbao y los socialistas europeos como Lamennais y Proudhon pero, cosa curiosa, defensor acérrimo del gobierno de Manuel Montt por considerar que el progreso no provendría sino del orden (Villalobos, 2009, p. 9). No estamos en condiciones de sopesar la tibia polémica que suscitó la recopilación y publicación de los Escritos

viene, en cambio, en El Chilote del 26/2/1880. Sobre su fecha de muerte, según Villalobos, Stuven y Schelchkov, ocurrió el 22 de febrero de 1884, en El Liberal del $7 / 3 / 1884$, en cambio, se informa que M.P. murió en la noche del 21 de febrero. 
políticos de Martín Palma ${ }^{37}$, una especie de reivindicación y ponderación del trabajo de este publicista que, a juicio de Andrey Schelchkov, cometería un error importante al considerarlo un mero difusor de ideas ajenas. Para Schelchkov (2013, pp. 114, 124-125), Palma habría sido "un pensador original con una visión propia del mundo, con proyectos sociales propios", y más aún, un innovador autor que combinó "el socialcristianismo, el anarquismo individualista y el liberalismo radical". Y por lo mismo, que debería ser considerado, junto a Francisco Bilbao y Santiago Arcos, como precursor del "socialismo y liberalismo social en Chile". Tremendo honor que este "precursor" fuera también precursor de otra práctica más bien contemporánea, al menos en Chile: la del retiro rural practicado por los intelectuales y artistas.

Uno de los episodios menos conocidos de la vida ya de por sí desconocida de Martín Palma, sería precisamente su estadía en Chiloé. El único que la menciona es Sergio Villalobos (2009, pp. 18-19), y al pasar, para ilustrar la decadencia en que habría caído Palma en los últimos años de su vida: "Ancud, una casucha de tablas en los dominios de la lluvia, y el frío... y las desdichas. Ejerce de maestro, enseña a leer a unos niños, e impenitente, no deja de colaborar graciosamente en un periódico local. Siempre hay algo que alabar o criticar para guiar a la gente".

Un poco más de información figura en los periódicos chilotes. Su primera aparición es en El Liberal del 7 de junio de 1879. Se trata de un inserto en que Palma agradece a don Juan Burr el que haya bautizado su nueva goleta con el nombre de Martín Palma. Una embarcación calificada el

37 Escritos políticos de Martín Palma, recopilados e introducidos por S. Villalobos y A.M. Stuven (ver los estudios citados en las notas anteriores), se publicó el año 2009.

38 e.g., un elogio al intendente Luis Martiniano Rodríguez (El Chilote del 25/12/1879), un artículo polemizando con el subsidio dado al Seminario de Ancud (El Chilote del 10/10/1879), otro polemizando con los clericales (El Liberal del 19/12/1879), sobre la importancia de Chiloé (El Liberal del 29/2/1880), un agradecimiento personal al médico de Quinchao (El Liberal del 1/6/1880) y, desde fines de 1880 a principios de 1881, fragmentos del libro La independencia humana, redactado en Dalcahue (El Liberal del 19/11/1880 al 4/2/1881).
19 de diciembre de 1879 en el mismo periódico como "hermosa y velera", destinada al tráfico y explotación de las guaneras, las loberías y la madera de Guaitecas. Tanto en este periódico como en El Chilote se insertaron regularmente artículos políticos de Martín Palma entre junio de 1879 y febrero de $1881^{38}$, en los que no se escatiman elogios al escritor, siendo incluso calificado como el escritor más prolífico de Chile, superado tan sólo por don Benjamín Vicuña Mackenna (El Liberal, edición del 24/2/1880).

Los motivos de su estadía en la provincia, aunque se nos mantienen ocultos, aparecen perfilados borrosamente por algunos comentarios de estos mismos periódicos que, además, aclaran que habría residido primero en Ancud para luego pasar a radicarse a una legua de Dalcahue (departamento de Quinchao) en febrero de 1880. Sus motivos para moverse al aislamiento del campo dalcahuino: buscar la "inspiración en el sosiego y tranquilidad cenobita, y en la bella poesía del campo, propiedad del poeta" (El Chilote, edición del 26/2/1880) o, sencillamente, por buscar un retiro "pero con árboles" que primero se proyectó en la pequeña isla Cochinos (bahía de Ancud) y posteriormente se concretó en Dalcahue, donde el redactor de El Liberal imaginó a Palma como uno de sus personajes, don Toribio de Guzmán de Los secretos del pueblo (El Liberal, edición del 24/2/1880) $)^{39}$

Parece por la cantidad, temática y calidad de artículos que se han referido, que Martín Palma se apropió de los problemas políticos y sociales de la provincia durante su estadía de cerca de dos años. Dentro de estos artículos, a nuestro juicio, el más importante sería "El general pililo y el

39 En una carta de Palma publicada en El Liberal el 16/10/1880, dirigida a David Goicolea (redactor del periódico), llegaría a calificar su residencia en Dalcahue como una soledad y "aislamiento casi absoluto", de lo que le pesaría sobre todo la falta de una biblioteca: aclara que sólo tiene para leer el Cosmos de Humboldt y el Evangelio, por lo que aprovecha de pedirle a Goicolea que le consiga en Ancud "El espíritu de las leyes de Montesquieu u otras obras de este género". En la misma nota, sin embargo, cita a Fourier. En otra publicación, El Liberal del 11/6/1880, M.P. afirma que vive en una casita "completamente aislada y debida a la complacencia generosa de un amigo, D. Juan Burr", y que disfruta esporádicamente de las visitas de Mariano Navarro y su hijo Felipe. 
chilote" (El Liberal, edición del 11/6/1880), en el que desarrolla una posición ya adelantada en otro texto del 29 de febrero de 1880, y que al parecer, constituía un tema de reflexión común en los redactores de la prensa chiloena ${ }^{40}$. Según Palma, Chiloé es Chile, aunque diferente y apartado; se le debe atender, se debe reconocer su patriotismo ${ }^{41}$. En sus palabras:

Si escribimos en Chiloé, es al país en general a quien nos dirigimos. [...]. Los ecos de esta apartada y olvidada Provincia también deben ser oídos, también deben repercutirse en los activos centros de nuestra República. No escuchar nuestra voz, sería negar nuestro patriotismo... sería ¡casi! segregarnos de la noble nacionalidad a que pertenecemos (El Liberal, edición del 29/2/1880).

En "El general pililo y el chilote" 42 , que ocupa prácticamente todo el número en que se publicó, esta idea de pertenencia del autor a Chiloé se diluye, pero, más importante, aparece con más fuerza y contenido la "fisonomía particular" o "el genio de un pueblo" que es el de la provincia de Chiloé, personificado en un sujeto al que alternadamente se refiere como 'chilote' o como 'piuco', utilizando esta última acepción en tono más coloquial que 'chilote' y como queriendo enfatizar el origen humilde del estereotipo, pero nunca asociado nominalmente a los indios, que en su extenso artículo no figuran ni siquiera como sombras, y tan importante como lo recién dicho, nunca asociado al contenido negativo de la voz 'piuco' (huraño, cerril, etcétera). Esta fisonomía, sin embargo, no se describe como un alegato nacionalista, a partir del cual podrían suponerse pretensiones separatistas, sino para recomendar al mandatario, al Intendente, que teniendo en cuenta

40 Ver e.g., el inserto firmado por David Goicolea en El Liberal del 26/12/1879 bajo el título "Los chilotes son también chilenos!". El autor hace un llamado a que todos los chilotes se presenten como reclutas voluntarios para probar que son chilenos. La idea de un pueblo chilote separado del pueblo chileno atraviesa todas sus reflexiones, con un dejo de desilusión patético.ç

41 En oposición, e.g., a las ideas negativas del patriotismo entendido como "preferencia hacia la propia nación" que sostendría el mismo Martín Palma en El cristianismo "esta manera de ser peculiar a cada nacionalidad y hasta peculiar a cada provincia" será más efectivo su gobierno y más efectivo el aporte de esta provincia al esfuerzo de la guerra y a la recluta:

Queremos venir a caer en el genio y en las tendencias de la provincia de Chiloé, $y$ esto con el fin de que los mandatarios, tomándolas en cuenta, las aprovechen sin contrariarlas, y saquen los recursos que sea susceptible de dar esta localidad, pero sin herirla en el corazón, sin agotar las fuentes productivas o lo que es lo mismo, sin acarrear con los padres de familia que son los hombres de labor, los que procuran el sustento a sus hijos que servirán a la Patria más tarde, los que dan vida y fuerzas a esta, de por sí, pobre provincia. Tómese el fruto, está bien, pero no se arrasen los árboles.

No hay espacio aquí para referirse al supuesto poco patriotismo de los habitantes de Chiloé, ni tampoco para hablar de los mecanismos utilizados por el intendente Luis Martiniano Rodríguez para compelerlos al esfuerzo bélico, en una recluta forzosa que comenzó en marzo de 1880 con destino a la frontera norte del país mapuche $e^{43}$. Acotémonos acá a la reflexión de Palma sobre el valor y las principales características del piuco, concepto utilizado por dicho autor como sinónimo de chilote popular.

Para Martín Palma, si bien los chilotes no eran cobardes, era claro que no querían ir a la guerra. Pruebas de su valentía podían verse en la temeridad con que se enfrentaban al mar en embarcaciones despreciables, y también, en la serenidad que mostraron durante las campañas bélicas de principios de siglo, durante la Independencia. Pues bien, si eran valerosos pero no querían ir a la guerra, Palma nos explica, es porque "el valor de los unos y de los otros es distinto". Y aquí nuestro

político, o reflexiones sobre el hombre y las sociedades, publicado en 1858 (Cid \& Torres, 2009, pp. 44-45).

42 Todas las citas siguientes, salvo que se diga lo contrario, corresponden a este artículo publicado, como se ha mencionado anteriormente, en El Liberal del día viernes 11 de junio de 1880 , a cuatro días de la toma de Arica.

43 Ver El Liberal, edición del 26/3/1880; El Chilote, ediciones del 28/3/1880 y 1/4/1880; ANH.DSM s.v., carta de Luis Martiniano Rodríguez a Domingo Santa María del 21/3/1880. 
Tabla 1. El roto y el piuco según Martín Palma.

\begin{tabular}{|c|c|}
\hline El roto / el general pililo: & El piuco/el chilote \\
\hline Se precipita sin mirar el peligro & "afronta y no retrocede" \\
\hline "impetuoso hasta la temeridad" & "sereno hasta la muerte" \\
\hline "marcha siempre adelante" & "no echa jamás un pie atrás" \\
\hline "sabe más bien matar" & "sabe más bien morir" \\
\hline "tiene el valor en la cabeza" & "tiene el valor en el corazón" \\
\hline "lo atropella todo" & "lo resiste todo" \\
\hline $\begin{array}{l}\text { "soporta las fatigas con entereza y se divierte con un chiste o } \\
\text { las echa al viento con un ca...nasto" }\end{array}$ & $\begin{array}{c}\text { "lleva esas fatigas con resignación y se consuela con una } \\
\text { plegaria" }\end{array}$ \\
\hline "va al combate por gusto" & "por deber" \\
\hline "tiene el ímpetu" & "la resistencia" \\
\hline $\begin{array}{l}\text { "es bullicioso, divertido, alegre como el champaña. Podría } \\
\text { decirse que es muy bueno para Postres" }\end{array}$ & $\begin{array}{c}\text { "es vigoroso y seco como el Oporto. Podría decirse que es } \\
\text { muy bueno para después de la Sopa" }\end{array}$ \\
\hline "es expansivo y chusco" & "reservado y serio" \\
\hline "tiene todos los defectos de la ligereza" & "todas las faltas de la terquedad" \\
\hline
\end{tabular}

Fuente: El Liberal, edición del 11/6/1880.

autor pasa a realizar un contrapunto entre los unos, los rotos, y los otros, los piucos, que se inicia con un elemental determinismo geográfico: los rotos son más susceptibles de entusiasmo, por el clima donde habitan, que es más ardiente; mientras que los piucos son más susceptibles de reflexión, por el clima más húmedo y frío en que viven. Veamos en la Tabla 1 algunos otros puntos de comparación entre el roto y el piuco (Tabla 1 ).

Dos hermanos diferentes, concluye Palma, "pero por cuyas venas corre la misma sangre: el valor, pues son hijos de una misma madre: Chile". Dos hermanos, ni mejores ni peores, sino complementarios (como la actividad y la pasividad, que parecen distinguir a uno y otro), destacando de los chilotes, fuera del tráfago de sentencias recién citadas, "la sumisión, el respeto a la autoridad, la firmeza en el cumplimiento del deber, independiente de su constancia en las empresas, de su prudencia y de cierta reserva digna que está lejos de ser hipocresía" y que le parece más bien esa "timidez sencilla" del hombre "casi primitivo" que no obra por ignorar "cómo debe de obrar".

Distinto, y más aún, sintiendo "la idea genérica de la Patria" como "una abstracción que no comprende bien" y que no lo entusiasma "con todo el calor para ir hasta el sacrificio", el piuco tendría además otra cualidad: lejos de la ausencia de vínculos personales del "general pililo", el chilote tiene lazos que lo amarran, afectos más fuertes mientras más dulces, más indestructibles mientras más espontáneos. "En general, [el piuco] es miembro de una estensa familia [...] tiene ascendientes a quienes respeta y socorre; $y$ descendientes a quienes ama y alimenta". En último término, "el chilote no es, pues, uno sino múltiple, no se pertenece a él solo, sino a muchos; no vive esclusivamente para sí, sino para todos". Una identidad colectiva que lo "amarra", y que lo amarra doblemente en la medida de que todo chilote, para Palma, era propietario. De esta condición que recuerda fuertemente una concepción de sociedad de Antiguo Régimen, Palma colegiría la escasísima delincuencia de la provincia, la afabilidad del trato y en fin, la supuesta integridad, armonía y moralidad dominantes en la provincia, en claro contraste con "la volubilidad e inconstancia que caracteriza al roto del Norte".

Una última extensa cita de Palma, que redondea el encomio cubierto de descripción que hace de la población chiloena, así como su vocación pacifista:

Pero el chilote prefiere el trabajo al valor o hace consistir el valor en el trabajo. Su alegría se cifra en su cosecha, y su triunfo en el aumento de su producción. Toda su vanidad y toda su gloria está en la buena calidad de sus papas y en lo granado de las espigas de su 
trigo. Es arrogante intrépido, denodado como ninguno para abatir los árboles, desfrozar los terrenos, arrancar los troncos, y armado de su cañón Krupp "la hacha" y de su Remington "el hualato", entra en lucha abierta contra la agreste naturaleza, y al fin triunfa... y con las glorias de la victoria vienen las satisfacciones de la fortuna. Según esto, no es extraño tampoco que el chilote sin ser cobarde, prefiera la paz a la guerra [...]. Y que encuentre sus goces en la producción que es la vida, y no en la destrucción que es la muerte.

Es curioso, de todos modos, que fuera un chileno quien llegara a estas reflexiones encomiásticas del chilote, semejantes a las de la "arcadia cristiana" que imaginaron otros autores ${ }^{44}$. Y más aún, que fuera un chileno liberal, anticlerical $y$ de profundas inquietudes sociales. Un liberal que se habría instalado en la provincia por un par de años, en los últimos días de su existencia y desde donde, si bien colaboraría con la prensa (predominantemente liberal) y con los potentados locales, es más presumible imaginar como alguien aislado, bien fuera en su residencia ancuditana, bien fuera en la pequeña y apartada cabaña en Dalcahue, donde se instaló, como ya he comentado, a fines de febrero de 1880. ¿Su amistad con los potentados locales, como el comerciante y maderero Juan Burr, su benefactor, pudo haberlo conducido en su reseña de los piucos, al punto de que no pudiera identificar la impronta de Antiguo Régimen en la sociedad chilota que describió, de que no pudiera ver los mecanismos de compulsión laboral utilizados por los potentados y autoridades locales, etcétera? ¿O habrá sido, quizá, un desafío personal: lograr imaginar una unidad nacional donde era evidente que habían al menos dos identidades populares, claramente distintas y ajenas?

\section{CONCLUSIONES}

La discusión sobre el piuco de Chiloé, como hemos visto, no es una que pueda sostenerse con abundancia de referencias y reflexiones ajenas a la que se ha intentado acá. Se trata de un término, como podrán dar fe los historiadores de Chiloé, sin

44 Como e.g., Ángel Vásquez en la década de 1870, el mismo Francisco Cavada, y para fechas más tardías uso en la actualidad y prácticamente omitido en las fuentes con que usualmente se ha escrito la historia de las provincias australes. La palabra 'piuco', sin embargo, no debe echarse al olvido por esto. Una muestra importante de lo que pudo ser el piuco la hemos visto recién con la reflexión de Martín Palma en los intensos años con que se inició la década de 1880: el piuco pudo ser imaginado como ícono de la identidad chiloeña. Una posibilidad que dependía de la existencia y socialización de aquella voz, y más aún, de su marcada polisemia.

Ya hemos anotado antes que la voz 'piuco' vehiculaba significados disímiles en las décadas de 1870 y 1880: junto con denominar a alguien rústico, huraño, cerril, etcétera, parece haber sido utilizada para denominar al bajo pueblo y a los indígenas de Chiloé, y por último, a la totalidad de los habitantes de dicha provincia. Sin que sepamos por ahora si acaso aquellas personas tenían mal gusto y combinaban mal las prendas con que se vestían, parece una cosa cierta que esto sería lo característico de un piuco en las décadas centrales del siglo XX, para luego perderse la palabra en el desuso. Hoy ya no existen piucos, y nos aventuramos a creer que sería vano el esfuerzo por encontrar usos contemporáneos de esta voz en la provincia de Chiloé, o aun entre los grupos de migrantes chilotes que poblaron la Patagonia chilena y argentina.

$\mathrm{Su}$ destino ignoto, sin embargo, no debe intimidarnos. Volver sobre los piucos, en buena medida, es volver sobre la imaginación de la identidad regional chiloeña, de lo cual el esfuerzo de Martín Palma comentado en la sección anterior es sin duda el primer intento. Un intento, además, que consideró una manera de articular aquella identidad regional con la identidad nacional. El concepto 'piuco' de 1880, por lo mismo, bien pudo convertirse en ícono de lo chiloense, y en un insumo fundamental en el proceso de configurar la nación en Chiloé. Pero no, el concepto 'piuco' desapareció, nos atrevemos a decir, en buena parte subsumido por el gentilicio con que actualmente nos referimos a la población de Chiloé: chilote.

Como gentilicio, como término despectivo, y aún como palabra para denominar a los sectores populares de una provincia, pareciera que el piuco

\footnotetext{
(década de 1950) Arnoldo Santana.
} 
habla precisamente de los discursos raciales, los mismos que sostendrán el nacionalismo cultural de principios del siglo XX (y piénsese p.e. en la "raza chilena" de Nicolás Palacios ${ }^{45}$ ). Por último, ¡las cosas suceden cuando pueden suceder!, de modo que podríamos leer el esfuerzo intelectual de Martín Palma en 1880 como un antecedente aislado y olvidado de lo que realizarán, con éxito, aquel conjunto de intelectuales chilotes que fundaron la identidad regional de Chiloé. Y pensamos en Darío y Francisco Cavada, Antonio y Humberto Bórquez del Solar, Pedro Barrientos ${ }^{46}$. Quizá para 1880 la población de Chiloé todavía no se imaginaba en términos análogos al del nacionalismo chileno, no obstante lo cual sí utilizaba al menos una palabra con el potencial de servir a dicha imaginación, piuco, aunque con trazas incómodas (lo indígena, lo rústico) que el gentilicio 'chilote' aparentemente probaría no tener.

\section{AGRADECIMIENTOS}

Este trabajo es resultado de la investigación doctoral titulada "La provincia de Chile: construcción del Estado-nación en Chiloé, 18301880", presentada en El Colegio de México (2017). Se agradece la lectura del borrador de este artículo y los comentarios realizados oportunamente Diego Morales. Del mismo modo, se agradece la lectura y comentarios de los evaluadores anónimos, y el apoyo invaluable de Ximena Urbina.

\section{BIBLIOGRAFÍA}

Álvarez, A. (1947). Vocablos y modismos del lenguaje de Chiloé.

45 Como indica Subercaseaux (2007), Palacios no es el autor del concepto, que ya aparece en la década de 1880 , pero sí es su primer tratadista.

46 Existe un grupo anterior de escritores procedentes de las provincias australes que se organizaron en Santiago, donde se encontraban estudiando, para publicar un periódico titulado El Sur. De todos modos, sus pretensiones distaban enormemente de las del grupo señalado en el párrafo: les interesaba el progreso de sus provincias (Valdivia, Llanquihue y Chiloé) antes que la definición de sus identidades. El contexto en que se publicó ese periódico (1878-1879) no facilitó su continuidad. Sobre los autores citados en el párrafo es posible afirmar que colaboraron a la estandarización del gentilicio 'chilote', vinculándolo a cierta ideología del mestizaje, pero sin mestizos, sobre la
Anales de la Universidad de Chile, 65-66, 69-171.

Aravena, G. (2017). Chiloé 1826. El proceso de incorporación de Chiloé a la República de Chile, 1813-1831. Castro: Ediciones 1826.

Azócar, R. (1938). Gente en la isla. Santiago de Chile: Zig-Zag. Cañas Pinochet, A. (1910). Estudios de la lengua veliche. Trabajos del Cuarto Congreso Científico (1o. PanAmericano) celebrado en Santiago de Chile del 25 de diciembre de 1908 al 5 de enero de 1909, s.n., 143-330.

Cavada, F. (1910). Apuntes para un vocabulario de provincialismos de Chiloé (República de Chile): precedidos de una breve reseña histórica del archipiélago. Punta Arenas: Imprenta de El Asilo de Huérfanas.

Cavada, D. (1914). Vida isleña. Novela de costumbres lugareñas. Valdivia: Imprenta Central.

Cavada, F. (1914). Chiloé y los chilotes. Santiago de Chile: Universitaria. También se publicó en la RChHG, nº 8, 9, 10, 11, 12 y 13 (1912-1914).

Cavada, F. (1921). Diccionario Manual Isleño. Provincialismos de Chiloé(Chile). (De gran utilidad para los profesores de castellano y para los viajeros que visitan la región austral del pais). Santiago de Chile: Yolanda.

Cavada, F. (1940). Historia centenaria de la diócesis de Ancud. Trabajo publicado con motivo del primer centenario de la fundación de la diócesis. Ancud: Imprenta San Francisco - Padre Las Casas.

Cid, G. (2009). Un ícono funcional: la invención del roto como símbolo nacional, 1870-1888. En G. Cid \& A. San Francisco (Eds.), Nación y nacionalismo en Chile. Siglo XIX (tomo I, pp. 221-254). Santiago de Chile: Ediciones Centro de Estudios Bicentenario.

Cid, G. (2011). La Guerra contra la Confederación. Imaginario nacionalista y memoria colectiva en

cual no podemos extendernos acá. Por último, existe una referencia en Weber (1903, p. 39) a cierta memoria de un ilustre chilote anónimo (que no se ha podido ubicar), en la cual se afirma que para 1840 las personas de Chiloé utilizaban con orgullo el gentilicio 'chilote', en oposición a los chilenos del norte. En resumen: hay una discusión pendiente sobre este asunto. Es nuestro parecer que el uso del gentilicio 'chilote', tal como lo usamos hoy en día, data del siglo XX, sin embargo de lo cual existan precedentes, como el uso que hace Martín Palma en el artículo citado con anterioridad y como el nombre del primer periódico publicado en Chiloé, de tendencia liberal y regentado por personas oriundas del país del Mapocho: El Chilote (Ancud, 1868-1886). Esperamos poder extendernos sobre este asunto en otro lugar. 
el siglo XIX Chileno. Santiago de Chile: Ediciones Universidad Diego Portales.

Cid, G., \& Torres, I. (2009). Conceptualizar la identidad: Patria y nación en el vocabulario chileno del siglo XIX. En G. Cid \& A. San Francisco (Eds.), Nación y nacionalismo en Chile. Siglo XIX (tomo I, ppp. 23-51). Santiago de Chile: Ediciones Centro de Estudios Bicentenario.

Cornejo, T. (2005). Representaciones visuales de lo popular a fines del siglo XIX: imágenes, sujetos e identidades. En A. Araya et al. (Eds.), Del nuevo al viejo mundo: mentalidades y representaciones desde América (pp. 161-183). Santiago de Chile: Universidad de Chile.

Del Solar, F. (1875). Reparos al Diccionario de chilenismos del señor don Zorobabel Rodríguez. Santiago de Chile: Imprenta de Federico Schrebler.

Fernández, J. (2009). Diccionario político y social del mundo iberoamericano. La era de las revoluciones, 17501850. Vol. I. Madrid: Centro de Estudios Políticos y Constitucionales.

Figueroa, P. P. (1897, 1901). Diccionario biográfico de Chile. Santiago de Chile: Imprenta y encuadernación Barcelona.

García-Huidobro, C. (1864). Provincias meridionales de Chile. Su descripción según un viaje hecho a ellas. Anales de la Universidad de Chile, XXV, 439-489.

Gazmuri, C. (1992). El "48" chileno. Igualitarios, reformistas radicales, masones y bomberos. Santiago de Chile: Universitaria.

Gutiérrez, H. (2010). Exaltación del mestizo: la invención del roto chileno. Universum, 25(1), 122-139.

Koselleck, R. (2012 [2006]). Historias de conceptos. Estudios sobre semántica y pragmática del lenguaje político y social. Madrid: Trotta.

Lenz, R. (1979). Diccionario etimológico. De las voces chilenas derivadas de lenguas indigenas americanas. Santiago de Chile: Universidad de Chile - Seminario de filología hispánica.

León León, M. A. (2015a). Una provincia "enteramente insular": geografía, exploraciones y cotidianeidad en Chiloé republicano, Chile (1826-1900). Magallania, 43(1), 53-68.

León León, M. A. (2015b). Chiloé en el siglo XIX. Historia y vida cotidiana de un mundo insular. Valparaíso: Ediciones Universitarias de Valparaíso.

Llorca-Jaña, M., Robles, C., \& Navarrete, J. (2018). Chiloé, una sociedad rural igualitaria. Distribución del ingreso agrícola y de la tierra después de la independencia. Magallania, 46(2), 58-105.
Mansilla, L. (1911). Relación genealógica de varias familias de Chiloé. Angol: El Colono.

Medina, J.T. (1928). Chilenismos. Apuntes lexicográficos. Santiago de Chile: Universo.

Morales, D. (2014). El negocio de la madera: comerciantes y hacheros de Chiloé, 1850-1875. Magallania, 42(2), 41-60.

Morales, D. (2016). Un puerto maderero en el sur de Chile. Ancud en los años cincuenta del siglo XIX. Magallania, 44(2), 87-105.

Ortega, L. (2005). Chile en ruta al capitalismo. Cambio, euforia y depresión 1850-1880. Santiago, DibamLom.

Palacios, N. (1904). Raza chilena: libro escrito por un chileno i para los chilenos. Valparaíso.

Pinto V., J. (1997). ¿Patria o clase? La Guerra del Pacífico y la reconfiguración de las identidades populares en el Chile contemporáneo. Contribuciones Científicas y Tecnológicas, 116, 43-56.

RAE (1925). Diccionario de la lengua española. Décima quinta edición. Madrid: Calpe.

Rodríguez, Z. (1875). Diccionario de chilenismos. Santiago de Chile: Imprenta de El Independiente.

Román, M. A. (1901-18). Diccionario de chilenismos y de otras voces y locuciones viciosas. Santiago de Chile: Imprenta de La Revista Católica. Cinco tomos.

Salinas, M. (2004). Los rotos y la nación: Juan Rafael Allende entre la Guerra del Pacífico y la Guerra civil de 1891. Mapocho, 55, 211-218.

Sater, W. (1986). Chile and the War of the Pacific. USA: The University of Nebraska Press.

Schelchkov, A. (2013). Emergiendo del olvido: Martín Palma, ¿utopista social? Estudios avanzados, 19, 109-127.

Stuven, A. M. (2009). Ilustración y religión en Chile: Martín Palma, un letrado liberal. En S. Villalobos \& A. M. Stuven (Eds.), Escritos políticos de Martín Palma (pp. 25-40). Santiago de Chile: Dibam-CIDBA.

Subercaseaux, B. (2007). Raza y nación: el caso de Chile. A contra corriente, 5(1), 29-63.

Tangol, N. (1944). Huipampa, tierra de sonámbulos. Santiago de Chile: Editorial Cultura.

Tangol, N. (1976). Diccionario etimológico chilote. Santiago de Chile: Nascimento.

Tornero, R.S. (1872). Chile ilustrado: guía descriptiva del territorio de Chile, de las capitales de provincia, de los puertos principales. Valparaíso: Imprenta y ajencia de El Mercurio.

Urbina Burgos, R. (2016). Ancud. Una capital provincial decimonónica 1800-1900. Valparaíso: Ediciones 
Universitarias de Valparaíso (PUCV).

Villalobos, S. (2009). La vida exagerada de Martín Palma y sus desdichas ocultas. En S. Villalobos \& A. M. Stuven (Eds.), Escritos politicos de Martín Palma (pp. 7-24).

\section{Dibam-CIDBA.}

Weber, A. (1903). Chiloé: su estado actual- su colonización, su porvenir. Santiago de Chile: Imprenta de Chile.

\section{Otras fuentes}

Archivo Nacional Histórico de Chile

Fondo Varios (ANH.FV).

Fondo Domingo Santa María (ANH.DSM).
Periódicos (Biblioteca Nacional de Chile)

El Chilote, Ancud, 1868-1886.

El Liberal, Ancud, 1878-1885.

La Probidad, Ancud, 1885-1890. 